\title{
Application of parallel stent placement in the treatment of unruptured vertebrobasilar fusiform aneurysms
}

\author{
*Jun Wang, PhD, Xin-Feng Liu, MD, Bao-Min Li, MD, Sheng Li, BD, Xiang-Yu Cao, PhD, \\ Yong-Ping Liang, PhD, Ai-Li Ge, BD, and Hui-Min Feng, BD \\ Department of Neurology, the General Hospital of PLA, Beijing, China
}

\begin{abstract}
OBJECTIVE Large vertebrobasilar fusiform aneurysms (VFAs) represent a small subset of intracranial aneurysms and are often among the most difficult to treat. Current surgical and endovascular techniques fail to achieve a complete or acceptable result because of complications, including late-onset basilar artery thrombosis and perforator infarction. The parallel-stent placement technique was established in the authors' department, and this study reports the application of this technique in the treatment of unruptured VFAs.
\end{abstract}

METHODS Eight patients with 8 unruptured VFAs who underwent parallel stent placement between April 2011 and August 2012 were included. The diameters of the VFAs ranged from 7.9 to $14.0 \mathrm{~mm}$, and the lengths from 27.5 to 54.4 $\mathrm{mm}$. Of the 8 patients with unruptured VFAs, 3 received double or triple parallel stents and 5 patients received a seriesconnected stent with another 1 or 2 stents deployed parallel to them. Outcomes for these patients were tabulated, based on the modified Rankin Scale (mRS) score and angiographic results.

RESULTS All of the 25 stents were successfully placed without any treatment-related complications. During follow-up, 5 patients had decreased mRS scores, 2 were unchanged, and 1 was increased for subarachnoid hemorrhage. Immediate and follow-up clinical outcome was completely or partially recovered in most patients. Follow-up angiograms revealed 2 aneurysms were reduced in size and 6 were unchanged after stent placement. No in-stent stenosis, occlusion of the posterior inferior cerebellar artery, or perforators jailed by the stent occurred in any of the aneurysms.

CONCLUSIONS These results provide encouraging support for the parallel-stent placement technique, which can be envisaged as an alternative strategy against unruptured VFAs. However, testing in more patients is needed.

http://thejns.org/doi/abs/10.3171/2015.12.JNS151716

KEY WORDS unruptured vertebrobasilar fusiform aneurysm; endovascular treatment; self-expandable stent; parallel stent placement; vascular disorders

$\mathrm{V}$ ERTEBROBASILAR fusiform aneurysms (VFAs), also known as vertebrobasilar dolichoectasia, are a vasculopathy characterized by pathologically enlarged, elongated, and abnormally tortuous vertebral and basilar arteries. The disorder has an estimated incidence of $0.06 \%-5.8 \%$. Fusiform aneurysms can be categorized as segmental ectasia, which have a stretched and fragmented internal elastic lamina, or dissecting aneurysms, which are characterized by widespread disruption of the elastic lamina, thickened intima, and extensive intraluminal thrombus..$^{20}$ VFAs present as frequently in the posterior circulation as in the anterior circulation, and they have an aggressive natural history. ${ }^{19}$ Fusiform aneurysms, which generally do not occur at arterial bifurcations, have a high probability for producing perforating branches. ${ }^{4}$ These aneurysms have several etiologies, and atherosclerotic degeneration, congenital defects, and segmental dysplasia of the arterial wall are believed to be predominating contributors. ${ }^{4}$ Patients with VFAs commonly manifest symptoms related to mass effects, including headaches, cranial nerve compression, ataxia, ischemic stroke secondary to dissection involving perforating branches or thromboembolic events, and subarachnoid hemorrhage (SAH). The natural history of these aneurysms leads to mortality rates at 5 years between $23 \%$ and $35 \%$, and these aggressive lesions cause an elevated risk of death within several days.,17

ABBREVIATIONS BA = basilar artery; DSA = digital subtraction angiography; $m R S=$ modified Rankin Scale; PCA = posterior cerebral artery; SAH = subarachnoid hemorrhage; VA = vertebral artery; VFA = vertebrobasilar fusiform aneurysm.

SUBMITTED July 23, 2015. ACCEPTED December 3, 2015.

INCLUDE WHEN CITING Published online March 25, 2016; DOI: 10.3171/2015.12.JNS151716.

* Drs. Wang and Liu contributed equally to this work. 
The management of unruptured fusiform aneurysms at the vertebrobasilar trunk remains controversial and challenging due to their complex morphology, and none of the available approaches have been shown to be comprehensively effective or low risk. ${ }^{18,19}$ In this study, multiple selfexpandable stents were placed in parallel (side by side) in vascular lesions with unruptured large VFAs. The purpose of this study was to evaluate the technical feasibility and efficacy of the parallel-stent placement technique in treating unruptured VFAs.

\section{Methods}

\section{Patient Population}

Institutional review board approval was obtained for the study from our hospital. Endovascular treatment was performed when it was considered the most appropriate treatment option after individualized evaluation by the vascular neurosurgeon and interventional neuroradiologist, taking into account collateral blood supply, aneurysm location and surgical accessibility, and patient preferences. All consecutive patients treated at our institution between April 2011 and August 2012 for unruptured fusiform aneurysms of the VBA trunk were included in this study. Eight posterior circulation aneurysms at the VBA trunk in 8 patients were managed using stent-only techniques. The 8 patients were all men with an average age of 55.50 years (range 42-71 years; Table 1). Ruptured cases with VBAs had been excluded from this study. For treating large fusiform aneurysms of the VBA trunk, commercially available intracranial stents, generally with a diameter less than $6 \mathrm{~mm}$, always exhibit unfavorable effects. We therefore designed this study to learn more about the possibility of treating large fusiform aneurysms by using multiple parallel stents, which have a better fit with the vascular wall and can prevent the size of the aneurysm from increasing. Eight patients with 8 aneurysms were managed by using parallel stent placement. Informed consent was obtained from all enrolled patients.

\section{Procedure Management}

Dual antiplatelet therapy (100 mg/day of aspirin as well as $75 \mathrm{mg} /$ day of clopidogrel) was routinely given to the patients with unruptured VFAs beginning 1 week before stent placement. In patients receiving parallel stent placement or series parallel stent placement, dual antiplatelet therapy was maintained for 12 months and then changed to aspirin monotherapy (100 mg/day). Activated coagulation time monitoring was performed from the beginning of the stenting procedure. A target activated coagulation time between 200 and 250 seconds was maintained, and a dose of 3000 units of heparin was injected intravenously just prior to stent deployment, followed by 1000 units of heparin per hour.

\section{Device and Deployment Technique}

To make the introduced stents fit better within the affected vascular segment with a large fusion aneurysm, multiple parallel stents (side by side) were deployed. With the guidance and assistance of a microcatheter, a selfexpanding stent was advanced over the prepositioned exchangeable guidewire and was deployed to cover the entire lesioned segment. Eight patients with 8 aneurysms at the VBA trunk were treated; 3 of these patients received double or triple parallel stents and 5 received a series-connected stent with another 1 or 2 stents deployed parallel to them (Table 2). The 2 series-connected stents must overlap by more than $5 \mathrm{~mm}$ to ensure the stability of the connection between them. The number and arrangement of the stents was determined according to the location, size (diameter and length), and shape of the aneurysms. The self-expanding stents used included Neuroform 2 stent (Boston Scientific) and Solitaire (ev3). Technical success was defined by correct placement of the stents.

\section{Clinical Assessment and Angiographic Follow-Up}

The initial neuroimaging evaluation included a nonenhanced CT scan or MRI sequence. For visualization of the aneurysm, all patients underwent CT angiography in addition to digital subtraction angiography (DSA); 3D DSA reconstruction was available for some patients.

Preoperative status and follow-up clinical outcomes were clinically assessed according to the modified Rankin Scale (mRS) score. Clinical outcomes were classified as improvement, unchanged, and aggravated, according to the mRS score change. Each patient's clinical status at the

TABLE 1. Characteristics of 8 patients with fusiform aneurysms in the vertebrobasilar arterial trunk

\begin{tabular}{|c|c|c|c|c|c|c|}
\hline $\begin{array}{l}\text { Case } \\
\text { No. }\end{array}$ & $\begin{array}{l}\text { Age } \\
\text { (yrs)* }\end{array}$ & $\begin{array}{l}\text { Aneurysm Diameter } \\
\times \text { Length }(\mathrm{mm})\end{array}$ & $\begin{array}{l}\text { Aneurysm } \\
\text { Location }\end{array}$ & $\begin{array}{l}\text { Previous Medical } \\
\text { Conditions }\end{array}$ & Mode of Presentation & Clinical Indications \\
\hline 1 & 47 & $8.7 \times 31.8$ & Lt VA & Smoking & Headache, dizziness, tinnitus & - \\
\hline 2 & 64 & $14.0 \times 39.0$ & Lt VA, BA & Hypertension & Headache, dizziness & - \\
\hline 3 & 71 & $9.1 \times 41.1$ & $\mathrm{BA}$ & Hypertension, smoking & Headache, dizziness & - \\
\hline 4 & 67 & $8.2 \times 50.7$ & Rt VA, BA & Smoking & Headache, slurred speech & $\begin{array}{l}\text { Oculomotor paralysis, hemifa- } \\
\text { cial spasm, dysarthria }\end{array}$ \\
\hline 5 & 49 & $9.6 \times 37.6$ & $\mathrm{BA}$ & Stroke, hypertension & Headache, slurred speech, dizziness & Dysarthria \\
\hline 6 & 53 & $7.9 \times 52.7$ & Lt VA, BA & Coronary artery disease & Headache, dizziness & - \\
\hline 7 & 42 & $11.9 \times 27.5$ & Lt VA, BA & Hypertension, smoking & Headache, dizziness & - \\
\hline 8 & 51 & $9.5 \times 54.4$ & Bilat VA, BA & Hypertension, diabetes & $\begin{array}{l}\text { Headache, slurred speech, myasthe- } \\
\text { nia of limbs, dizziness }\end{array}$ & Dysphagia, dysarthria \\
\hline
\end{tabular}

\footnotetext{
* All patients were male.
} 
TABLE 2. Summary of stents characteristics and follow-up data

\begin{tabular}{|c|c|c|c|c|c|c|}
\hline \multirow[b]{2}{*}{$\begin{array}{l}\text { Case } \\
\text { No. }\end{array}$} & \multirow[b]{2}{*}{ Stent Type/Size $(\mathrm{mm})$ \& Deployment } & \multirow[b]{2}{*}{ Immediate Symptoms } & \multirow[b]{2}{*}{ Follow-Up Symptoms } & \multirow[b]{2}{*}{ Follow-Up DSA/Mos } & \multicolumn{2}{|c|}{ mRS score } \\
\hline & & & & & Preop & $\begin{array}{l}\text { Last Follow-Up } \\
\text { (mos) }\end{array}$ \\
\hline 1 & NF $4.5 / 30$ parallel w/ SOL 6/30 & Mild tinnitus & No & Unchanged/14 & 1 & $0(18)$ \\
\hline 2 & $\begin{array}{l}\text { SOL } 6 / 30 \text { parallel w/ NF } 4.5 / 30 \text { parallel w/ } \\
\text { SOL } 6 / 30\end{array}$ & Mild headache & No & Improvement/21 & 2 & $1(21)$ \\
\hline 3 & $\begin{array}{l}\text { (NF } 4.5 / 30 \text { series w/ NF 4.5/30) parallel w/ } \\
\text { SOL 6/20 parallel w/ SOL 6/30 }\end{array}$ & Mild headache & No & Unchanged/23 & 2 & $1(23)$ \\
\hline 4 & $\begin{array}{l}\text { (NF } 4.5 / 30 \text { series w/ NF } 4.5 / 30 \text { ) parallel w/ } \\
\quad \text { SOL } 6 / 30\end{array}$ & $\begin{array}{l}\text { Relieved dysarthria \& } \\
\text { headache }\end{array}$ & $\begin{array}{l}\text { Dysarthria, incidental } \\
\text { headache }\end{array}$ & Unchanged/19 & 2 & $2(22)$ \\
\hline 5 & $\begin{array}{l}\text { NF } 4.5 / 30 \text { parallel w/ SOL6/30 parallel w/ } \\
\text { SOL6/20 }\end{array}$ & Relieved dysarthria & Relieved dysarthria & Unchanged/23 & 2 & $2(28)$ \\
\hline 6 & $\begin{array}{l}\text { (SOL 6/30 series w/ SOL 6/30) parallel w/ } \\
\text { NF } 4.5 / 30\end{array}$ & Mild headache & Incidental headache & Unchanged/18 & 3 & $2(24)$ \\
\hline 7 & $\begin{array}{l}\text { (NF } 4.5 / 30 \text { series w/ NF 4.5/30) parallel w/ } \\
\text { SOL6/30 }\end{array}$ & No & No & Improvement/21 & 1 & $0(24)$ \\
\hline 8 & $\begin{array}{l}\text { (NF 4.5/30 series w/ NF 4.5/30) parallel w/ } \\
\text { NF } 4.5 / 30 \text { parallel w/ SOL 6/30 }\end{array}$ & $\begin{array}{l}\text { Improved myasthenia } \\
\text { of limbs, dysarthria }\end{array}$ & $\begin{array}{l}\text { Myasthenia, dysarthria, } \\
\text { sudden SAH }\end{array}$ & Unchanged/4 & 4 & $6(5)$ \\
\hline
\end{tabular}

$\mathrm{NF}=$ Neuroform; $\mathrm{SOL}=$ Solitaire.

last clinical follow-up evaluation was defined as the final outcome. At least 1 angiographic follow-up was available in 8 patients at 14 to 23 months (mean 18 months) after treatment. The size of the aneurysmal sac was assessed by an interventional neuroradiologist (Y.P.L.), who was blinded to the treatment.

\section{Results \\ Descriptive Data}

Between April 2011 and August 2012,8 patients (mean age $55.50 \pm 10.47$ years) with 8 unruptured VFAs were successively admitted to our institution and treated with parallel stent placement according to the individualized evaluation by the vascular neurosurgeon and interventional neuroradiologist. Clinical characteristics are summarized in Table 1. The 8 aneurysms presented at a mean diameter of $9.86 \pm 2.07 \mathrm{~mm}$ (range 7.9-14.0 $\mathrm{mm}$ ) and length of $41.85 \pm 9.91 \mathrm{~mm}$ (range $27.5-54.4 \mathrm{~mm}$ ). The majority of the aneurysms were located in the left vertebral artery (VA) that extended to the basilar artery (BA). Five of the patients had a history of hypertension, 1 patient had coronary artery disease, and 1 patient had experienced ischemic stroke. Most of the patients experienced headaches and dizziness, with other brainstem compression symptoms such as dysarthria, dysphagia, and tinnitus. No aneurysms presented with SAH. The patients were referred to our department because of their presentation for approximately 5 days to 1 year.

Of the 8 giant VFAs, 3 were treated by parallel stenting only, and 5 by series stenting combined with parallel stenting. A total of 25 stents were deployed and an average of 3.13 stents (range 2-4 stents) were used to treat each aneurysm. All stents were successfully delivered to the target vessel. Angiography immediately after placement revealed that the deployed stents were well established and no overlapping stents became separated. No operation-related complications occurred.

\section{Clinical Outcomes}

Clinical and angiographic follow-up results of the patients are summarized in Table 2. Stent placement was successfully accomplished without any treatment-related complications in all 8 patients. The mean angiographic follow-up duration was $17.88 \pm 6.33$ months (range $4-23$ months). During the periprocedural periods, no deaths, distal embolism, or ischemic stroke occurred. One patient presented with transient ischemic attack. In the delayed follow-up, 1 patient died due to hemorrhage at 5 months postoperatively. The mean $\mathrm{mRS}$ score decreased from $2.13 \pm 0.99$ to $1.75 \pm 1.91$, and the clinical outcomes of 5 patients improved, 2 were unchanged, and 1 patient became worse and died of SAH. The follow-up angiographic results revealed that 2 aneurysms decreased in size and 6 were unchanged. None of the aneurysms in this study showed in-stent stenosis, occlusion of the posterior inferior cerebellar artery, or perforators jailed by the stent.

\section{Illustrative Cases \\ Case 2}

A 64-year-old man presented to our department with headache and dizziness. On MRI, a large VFA with brainstem compression was apparent (Fig. 1A). A left VA angiogram and 3D reconstruction confirmed a giant VFA (maximum diameter $14.0 \mathrm{~mm}$, length $39.0 \mathrm{~mm}$ ) that extended from the $V_{4}$ segment of the left VA up to the proximal segment of the BA (Fig. 1B-D). The aneurysm was treated with 3 telescopically implanted parallel intracranial stents. Under general anesthesia, an 8-Fr guiding catheter (Guider MPA, Cordis) was positioned at the left VA. A microcatheter (Prowler14 Select Plus; Codman Neurovascular) 

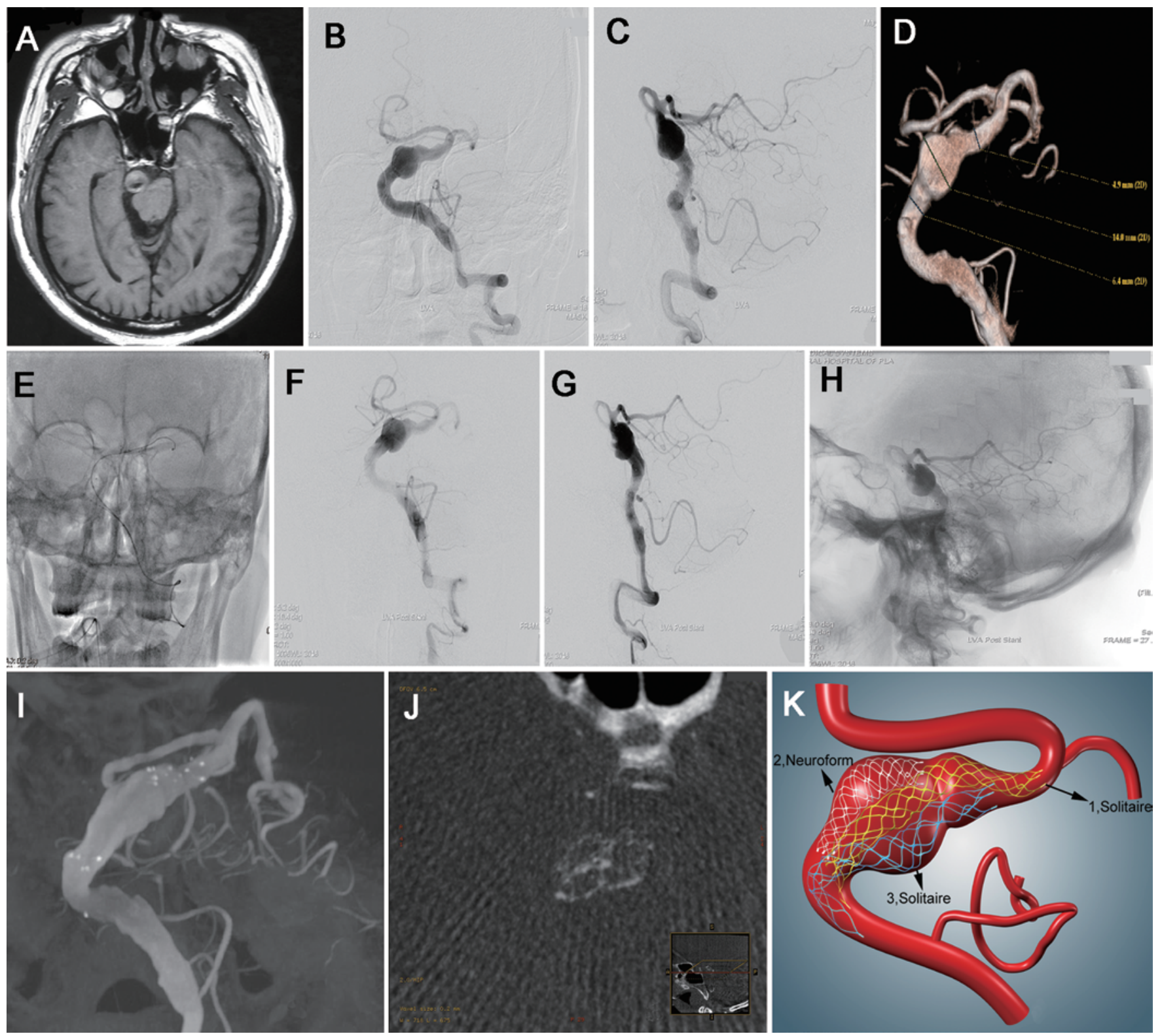

FIG. 1. Case 2. A 64-year-old man with VFA presented with headache, dizziness, and tinnitus. MRI showed a large VFA with brainstem compression (A). Anteroposterior (B) and lateral (C) views of a preoperative left VA angiogram revealed a giant fusiform aneurysm in the vertebrobasilar arterial trunk. A preoperative anteroposterior 3D CT angiogram showed a VFA with a maximum diameter of $14.0 \mathrm{~mm}$ (D). An unsubtracted DSA (E) showed the 3 stents (Solitaire $6 \times 30 \mathrm{~mm}$, Neuroform $4.5 \times 30 \mathrm{~mm}$, Solitaire 6 $\times 30 \mathrm{~mm}$ ) deployed in parallel by the guidewire and positioned in the left PCA. Immediate preoperative angiograms (F and $\mathbf{G})$, an unsubtracted digital subtraction angiogram $(\mathrm{H})$ of the aneurysm, and anteroposterior and axial angiograms (I and $\mathrm{J}$ ) acquired after deployment of the stents are shown. An illustration shows the definitive parallel placement of stents after deployment (K). Figure is available in color online only.

was navigated through a 0.014 -inch microguidewire (Essence, Codman) and placed into the left posterior cerebral artery (PCA). An X-celerator microguidewire (0.014-inch diameter, 300-cm length; X-celerator300, ev3) was placed into the $\mathrm{P}_{1}$ segment of the left PCA through this microcatheter. A Rebar-27 catheter (ev3) was navigated through the 0.014-inch microguidewire (Essence, Codman) and placed into the distal BA (Fig. 1E). A Solitaire stent $(6.0 \times$ $30 \mathrm{~mm}$ ) was advanced through the Rebar-27 catheter and completely deployed into the aneurysmal sac distally. The second stent (Neuroform $4.5 \times 30 \mathrm{~mm}$, Boston Scientific) was navigated through the $\mathrm{X}$-celerator microguidewire (0.014 inch/300 cm, X-celerator300, ev3) and placed 10 $\mathrm{mm}$ proximal to the head end of the first stent, and incompletely (one-third) deployed. A Rebar-27 catheter (ev3) was navigated through the 0.014-inch microguidewire (Essence, Codman) and placed next to this incompletely deployed stent. The third stent (Solitaire $6.0 \times 30 \mathrm{~mm}$, ev3) was advanced through the Rebar-27 catheter and deployed completely (Fig. 1I and J). The placement of the 3 stents 
is illustrated in Fig. 1K. The immediate postprocedure angiograms revealed that 3 stents were successfully deployed, and the flow of the giant VFA was attenuated (Fig. $1 \mathrm{~F}-\mathrm{H})$. After the operation, the patient experienced mild headache, which greatly improved during follow-up (Table 2). Follow-up angiography at 6 months revealed progressive thrombosis, while no remarkable change in size or configuration of the aneurysm occurred (Fig. 2A and B). Nineteen months after the procedure, DSA revealed that the aneurysmal sac had decreased in size, especially in the proximal segment of the BA (Fig. 2C and D). The maximum diameter of the aneurysm based on DSA and $3 \mathrm{D}$ reconstruction had been reduced by $32.1 \%(14.0 \mathrm{~mm}$ preoperatively vs $9.5 \mathrm{~mm}$ postoperatively; Fig. 2E). Clinically, the patient was asymptomatic.

\section{Case 4}

A 67-year-old man presented with headaches, oculomotor paralysis, dysarthria, hypesthesia of the left side of the face, and sensory deficits in the right upper and lower extremity. He had undergone internal carotid artery stent placement 10 months previously. The DSA revealed a large VFA (maximum diameter $8.2 \mathrm{~mm}$, length $50.7 \mathrm{~mm}$; Fig. 3A). The aneurysm was treated by 2 telescopically inserted overlapping Neuroform $4.5 \times 30 \mathrm{~mm}$ stents side by side with a Solitaire $6.0 \times 30 \mathrm{~mm}$ stent. The postprocedure angiograms showed that bilateral posterior circula- tion was well preserved (Fig. 3B). Cranial nerve palsies were partially recovered immediately after the operation. A follow-up angiogram at 9 months showed that the aneurysm was unchanged in size, and no detachment or shift of the deployed stents occurred, as shown in the CT scan (Fig. 3C-F). During follow-up, the patient continued to experience dysarthria and incidental headache with an unchanged mRS score.

\section{Discussion}

Large or giant VFAs, a well-known cause of acute SAH or ischemic stroke of the posterior circulation, constitute a relatively small, uncommon subgroup of aneurysms. Our study reported a new stent-only therapeutic endovascular approach for posterior circulation aneurysms. Multiple self-expandable stents were deployed in parallel in the treatment of 8 aneurysms, and follow-up outcomes showed that most of the patients had improved and had stable symptoms as reflected by the reduced mRS scores, decreased aneurysm size, and few delayed complications. VFAs remain one of the most formidable lesions due to their size, location, and morphology, and no firmly accepted management paradigm is currently available. Traditional surgical clipping techniques are gradually falling out of favor due to unsatisfactory results and high surgical risk, and a variety of endovascular treatment strategies

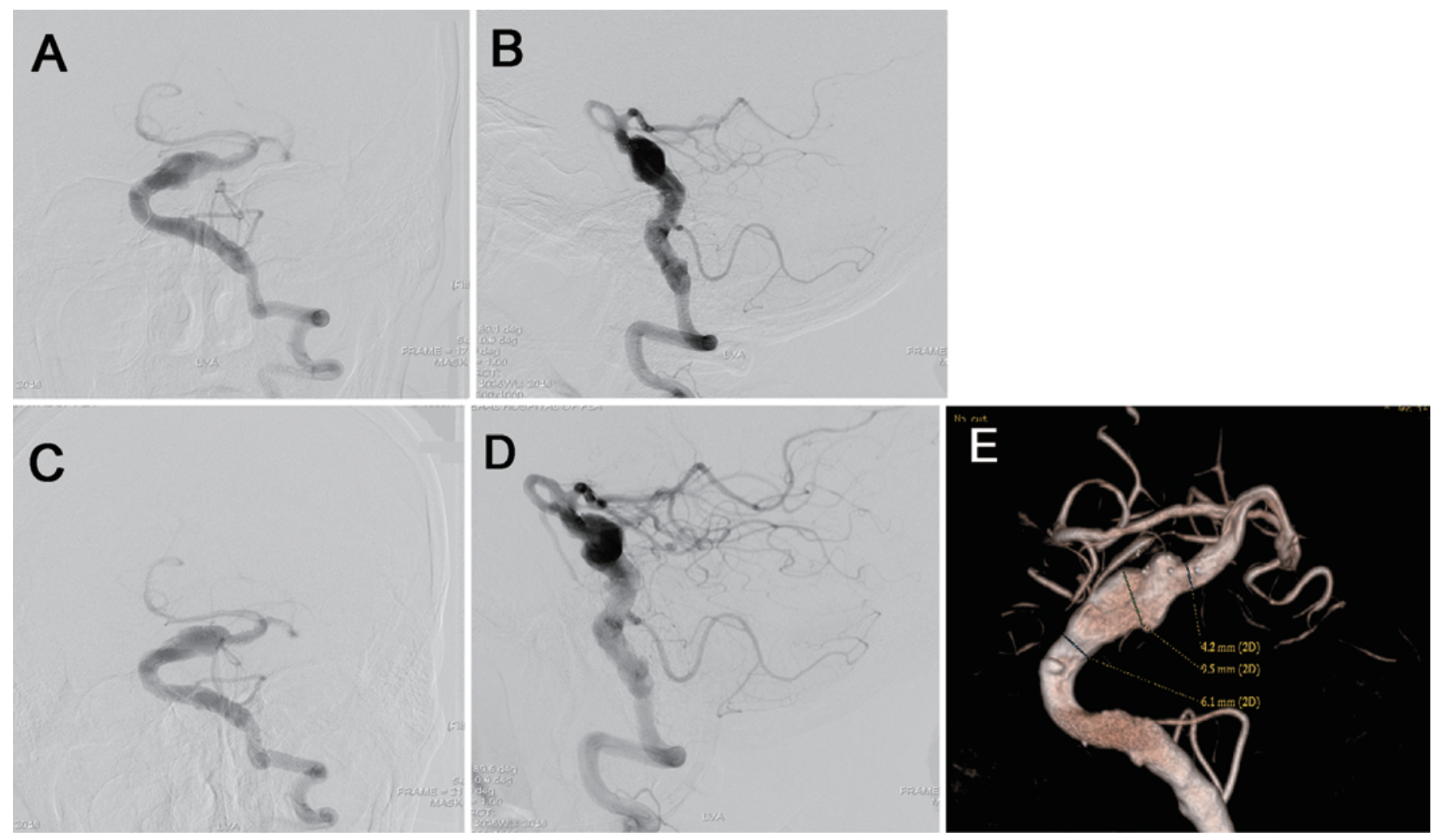

FIG. 2. Case 2. Follow-up angiograms of the VFA treated with parallel stent placement. Anteroposterior (A) and lateral (B) views of angiograms acquired 6 months after deployment of the stents. Anteroposterior and lateral views of angiograms acquired 19 months after deployment of the stents (C-D). Anteroposterior 3D CT angiogram acquired 19 months after deployment of stents (Solitaire $6 \times 30 \mathrm{~mm}$, parallel with Neuroform $4.5 \times 30 \mathrm{~mm}$, parallel with Solitaire $6 \times 30 \mathrm{~mm}$ ) revealed that the fusiform aneurysm was reduced in size, with a maximum diameter of $9.5 \mathrm{~mm}(\mathrm{E})$. Figure is available in color online only. 


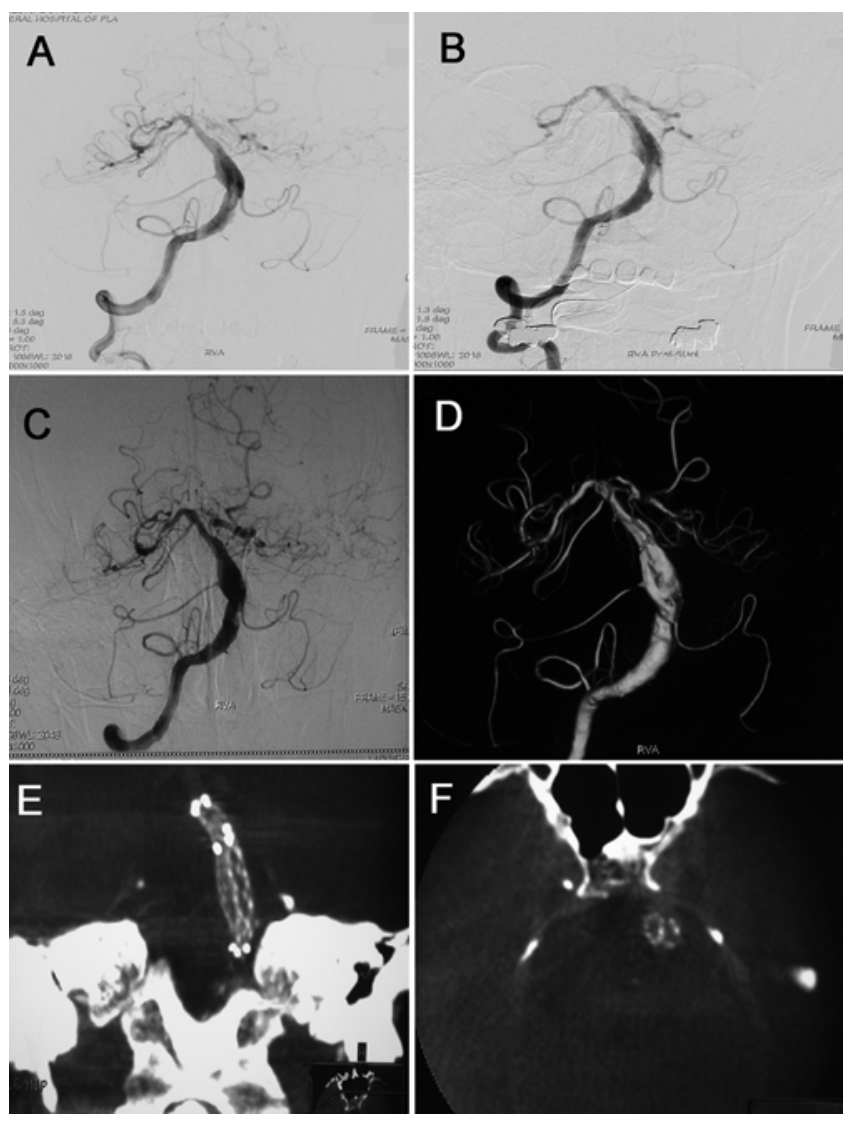

FIG. 3. Case 4. A 67-year-old man with VFAs and occlusion of the right carotid artery presented with headaches, dysarthria, and sensory deficits. $A$ and $B$ : An anteroposterior view of a right VA angiogram before (A) and after (B) stenting of the fusiform aneurysm. C-F: Follow-up angiogram (C) and DSA 3D reconstruction (D), as well as axial and coronal 3D CT images ( $E$ and $F$ ) at 9 months.

are being used as the first-choice treatment of VBAs. ${ }^{5,16}$ To date, flow diverters, stent-assisted coil embolization, and stent-only therapy with single or multiple stents comprise the main techniques in treating VFAs. ${ }^{4,12,20,23}$ Flow-diverting stents, including the Pipeline embolization device and Silk stent, are characterized by much higher metal coverage and lower porosity. ${ }^{6}$ Flow-diverting stents have received US FDA approval for large anterior circulation intracranial aneurysms and gained momentum as a curative approach for complex aneurysms. ${ }^{10,13,14}$ Moreover, Phillips et al. showed the Pipeline embolization device is effective in the treatment of posterior circulation aneurysms and exhibits safety comparable to that of stent-assisted coiling techniques. However a higher clinical perforator infarction rate and late-onset BA thrombosis (after 2 years) has also been documented concerning the application of the Pipeline embolization device or Silk stent. ${ }^{1,13}$ Stent-assisted coil embolization is an endovascular reconstructive technique and takes advantage of the parent vessel preservation, which obviates the need to consider whether collateral blood flow is sufficient to allow parent vessel sacrifice without neurological deficit. ${ }^{8,9,22}$ Stent-assisted coil embolization in the perforator-rich vertebrobasilar system also contributes to thrombotic occlusion of perforating vessels and subsequent ischemic complications, and ultimately to perforator stroke. ${ }^{9,15}$ Therefore, these devices should be chosen judiciously. ${ }^{12,19}$

In more recent years, a stent-only approach has been used and has achieved excellent results. Park et al. reported that stent-only therapy (balloon-expandable or self-expanding stents) was safe and effective in the treatment of vertebrobasilar dissecting aneurysms, and use of a single stent for aneurysms in the posterior circulation complex was shown to be a safe and effective technique. ${ }^{11,23}$ To treat large VFAs, double or triple self-expandable stents deployed in series (placed end to end) were documented in several reports. ${ }^{21}$ Ansari et al. used overlapping Neuroform stents to treat fusiform intracranial aneurysms and revealed that they can induce spontaneous thrombosis of intracranial aneurysms and facilitate parent artery reconstruction through flow remodeling and stent endothelialization. $^{2}$

However, because of their size and irregular morphology, large VFAs are difficult to treat by single stenting or series stenting. These stents cannot completely obliterate the dissecting aneurysm sac, and the inflow is dispersed into the aneurysm sac. A single stent or stents in a series cannot stabilize the vessel wall to the best effect. Ultimately, the large VFAs treated with single stenting or series stenting might enlarge and be exacerbated. Therefore, in our clinical practice, the stents were placed in parallel for the first time in 8 patients with large VFAs because the self-expandable stents have better adaptability to the tortuous vessels, have low radial force, and are less traumatic. The results showed that no worsening occurred in the 8 patients after the operation, indicating that parallel stent placement successfully prevented the enlargement of large VFAs. In addition, the outcomes of 2 patients were found to be improved at follow-up angiography, indicating that the parallel-stenting technique reversed the development of the giant VFAs.

Parallel stenting still has several limitations. This treatment is not suitable for ruptured VFAs because the selfexpandable stents are too porous to support intraluminal thrombosis and prevent bleeding. ${ }^{7}$ Moreover, there is a high risk of delayed stent thrombosis. The possibility of the perforators covered by the stent becoming occluded is another major concern in stent therapy, especially for the perforator-rich vertebrobasilar system. In addition, a small number of patients and a relatively short follow-up duration also prevent definitive conclusions from our study. Further investigation and clinical trials are required.

\section{Conclusions}

Parallel stent placement may be a feasible and alternative technique in the treatment of unruptured VFAs. However, a larger series of patients is required to support our evidence.

\section{Acknowledgments}

This work was supported by the Natural Science Foundation of China (grant no. 81371296) and a Special Research Project for Capital Health Development (grant no. 2014-1-1071). 


\section{References}

1. Ahmed O, Storey C, Kalakoti P, Deep Thakur J, Zhang S, Nanda A, et al: Treatment of vertebrobasilar fusiform aneurysms with Pipeline embolization device. Interv Neuroradiol 21:434-440, 2015

2. Ansari SA, Lassig JP, Nicol E, Thompson BG, Gemmete JJ, Gandhi D: Thrombosis of a fusiform intracranial aneurysm induced by overlapping neuroform stents: case report. Neurosurgery 60:E950-E951, 2007

3. Cappellari M, Tomelleri G, Piovan E, Bovi P, Moretto G, Gulli G: Chronic fusiform aneurysm evolving into giant aneurysm in the basilar artery. Neurol Sci 33:111-115, 2012

4. Gobin YP, Viñuela F, Gurian JH, Guglielmi G, Duckwiler GR, Massoud TF, et al: Treatment of large and giant fusiform intracranial aneurysms with Guglielmi detachable coils. J Neurosurg 84:55-62, 1996

5. Hoh BL, Putman CM, Budzik RF, Carter BS, Ogilvy CS: Combined surgical and endovascular techniques of flow alteration to treat fusiform and complex wide-necked intracranial aneurysms that are unsuitable for clipping or coil embolization. J Neurosurg 95:24-35, 2001

6. Kerolus M, Kasliwal MK, Lopes DK: Persistent aneurysm growth following pipeline embolization device assisted coiling of a fusiform vertebral artery aneurysm: a word of caution! Neurointervention 10:28-33, 2015

7. Kim M, Taulbee DB, Tremmel M, Meng H: Comparison of two stents in modifying cerebral aneurysm hemodynamics. Ann Biomed Eng 36:726-741, 2008

8. Lubicz B, Bandeira A, Bruneau M, Dewindt A, Balériaux D, De Witte O: Stenting is improving and stabilizing anatomical results of coiled intracranial aneurysms. Neuroradiology 51:419-425, 2009

9. Lubicz B, Collignon L, Lefranc F, Bruneau M, Brotchi J, Balériaux D, et al: Circumferential and fusiform intracranial aneurysms: reconstructive endovascular treatment with selfexpandable stents. Neuroradiology 50:499-507, 2008

10. Lubicz B, Collignon L, Raphaeli G, Pruvo JP, Bruneau M, De Witte O, et al: Flow-diverter stent for the endovascular treatment of intracranial aneurysms: a prospective study in 29 patients with 34 aneurysms. Stroke 41:2247-2253, 2010

11. Park SI, Kim BM, Kim DI, Shin YS, Suh SH, Chung EC, et al: Clinical and angiographic follow-up of stent-only therapy for acute intracranial vertebrobasilar dissecting aneurysms. AJNR Am J Neuroradiol 30:1351-1356, 2009

12. Parkinson RJ, Eddleman CS, Batjer HH, Bendok BR: Giant intracranial aneurysms: endovascular challenges. Neurosurgery 62 (6 Suppl 3):1336-1345, 2008

13. Phillips TJ, Wenderoth JD, Phatouros CC, Rice H, Singh TP, Devilliers L, et al: Safety of the Pipeline Embolization Device in treatment of posterior circulation aneurysms. AJNR Am J Neuroradiol 33:1225-1231, 2012

14. Pierot L: Letter by Pierot regarding article "Flow-diverter stent for the endovascular treatment of intracranial aneurysms: a prospective study in 29 patients with 34 aneurysms." Stroke 42:e38-e40, 2011 (Letter)

15. Piotin M, Blanc R, Spelle L, Mounayer C, Piantino R, Schmidt PJ, et al: Stent-assisted coiling of intracranial aneu- rysms: clinical and angiographic results in 216 consecutive aneurysms. Stroke 41:110-115, 2010

16. Rabinov JD, Hellinger FR, Morris PP, Ogilvy CS, Putman $\mathrm{CM}$ : Endovascular management of vertebrobasilar dissecting aneurysms. AJNR Am J Neuroradiol 24:1421-1428, 2003

17. Raphaeli G, Collignon L, De Witte O, Lubicz B: Endovascular treatment of posterior circulation fusiform aneurysms: single-center experience in 31 patients. Neurosurgery 69:274-283, 2011

18. Sacho RH, Saliou G, Kostynskyy A, Menezes R, Tymianski M, Krings T, et al: Natural history and outcome after treatment of unruptured intradural fusiform aneurysms. Stroke 45:3251-3256, 2014

19. Siddiqui AH, Abla AA, Kan P, Dumont TM, Jahshan S, Britz GW, et al: Panacea or problem: flow diverters in the treatment of symptomatic large or giant fusiform vertebrobasilar aneurysms. J Neurosurg 116:1258-1266, 2012

20. van Oel LI, van Rooij WJ, Sluzewski M, Beute GN, Lohle PN, Peluso JP: Reconstructive endovascular treatment of fusiform and dissecting basilar trunk aneurysms with flow diverters, stents, and coils. AJNR Am J Neuroradiol 34:589-595, 2013

21. Wakhloo AK, Mandell J, Gounis MJ, Brooks C, Linfante I, Winer J, et al: Stent-assisted reconstructive endovascular repair of cranial fusiform atherosclerotic and dissecting aneurysms: long-term clinical and angiographic follow-up. Stroke 39:3288-3296, 2008

22. Wang Q, Leng B, Song D, Chen G: Fusiform aneurysms of the vertebrobasilar arterial trunk: choice of endovascular methods and therapeutic efficacy. Acta Neurochir (Wien) 152:1467-1476, 2010

23. Zenteno MA, Santos-Franco JA, Freitas-Modenesi JM, Gómez C, Murillo-Bonilla L, Aburto-Murrieta Y, et al: Use of the sole stenting technique for the management of aneurysms in the posterior circulation in a prospective series of $20 \mathrm{pa}-$ tients. J Neurosurg 108:1104-1118, 2008

\section{Disclosures}

The authors report no conflict of interest concerning the materials or methods used in this study or the findings specified in this paper.

\section{Author Contributions}

Conception and design: B Li, Wang. Acquisition of data: B Li, Wang, Liu, S Li, Cao, Liang, Feng. Analysis and interpretation of data: B Li, Wang, Liu, S Li, Cao, Ge. Drafting the article: Wang. Critically revising the article: Wang, Liu, S Li. Reviewed submitted version of manuscript: B Li, Wang. Approved the final version of the manuscript on behalf of all authors: B Li. Statistical analysis: Liu, S Li, Cao, Liang, Ge, Feng. Administrative/technical/material support: B Li. Study supervision: B Li.

\section{Correspondence}

Bao-Min Li, Department of Neurology, PLA General Hospital, 28 Fuxing Rd., Beijing 100853, China. email: lbm301@189.com. 